\title{
Optical education in the USSR
}

Gregory Altshuler, Elena Doulneva

Gregory B. Altshuler, Elena G. Doulneva, "Optical education in the USSR," Proc. SPIE 1603, Education in Optics, (1 March 1992); doi: 10.1117/12.57841

SPIE. Event: Education in Optics, 1991, Leningrad, Russian Federation 
Optical education in the USSR

Grigori B.Altshuler, Elena G.Doulneva

Institute of Fine Mechanics and Optics,

Quantum Electronics Department, St.Petersburg, Russia

You know that in the large entity until recently called the USSR, great changes have taken place. The educational system also changes. The contents of our report relate to the system of optical education which has been used up to the end of the 80-ies. In conclusion I'll try to discuss the basic trends of its reformation. All figures and data in our report correspond to the USSR within its borders before August, 191991.

\section{GENERAL CHARACTERISTICS OF EDUCATION IN THE USSR}

Until recently the USSR was weakly connected with the rest of the world and therefore here, all trends of science and engeneering developed independely on their abilities to compete.

1 stage

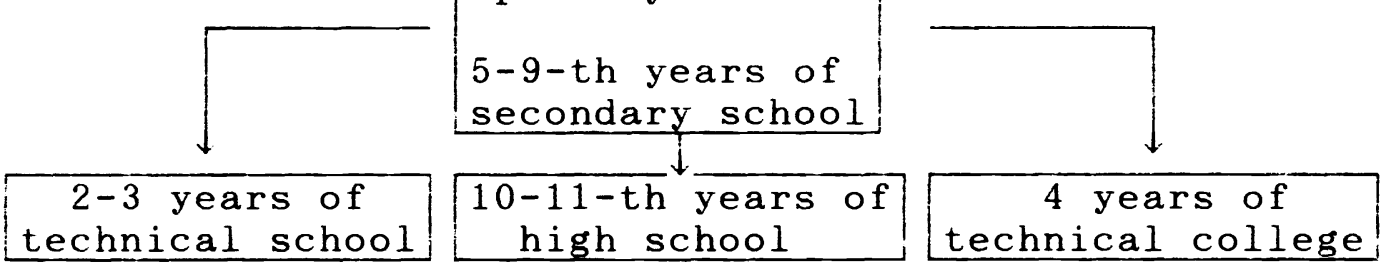

2 stage

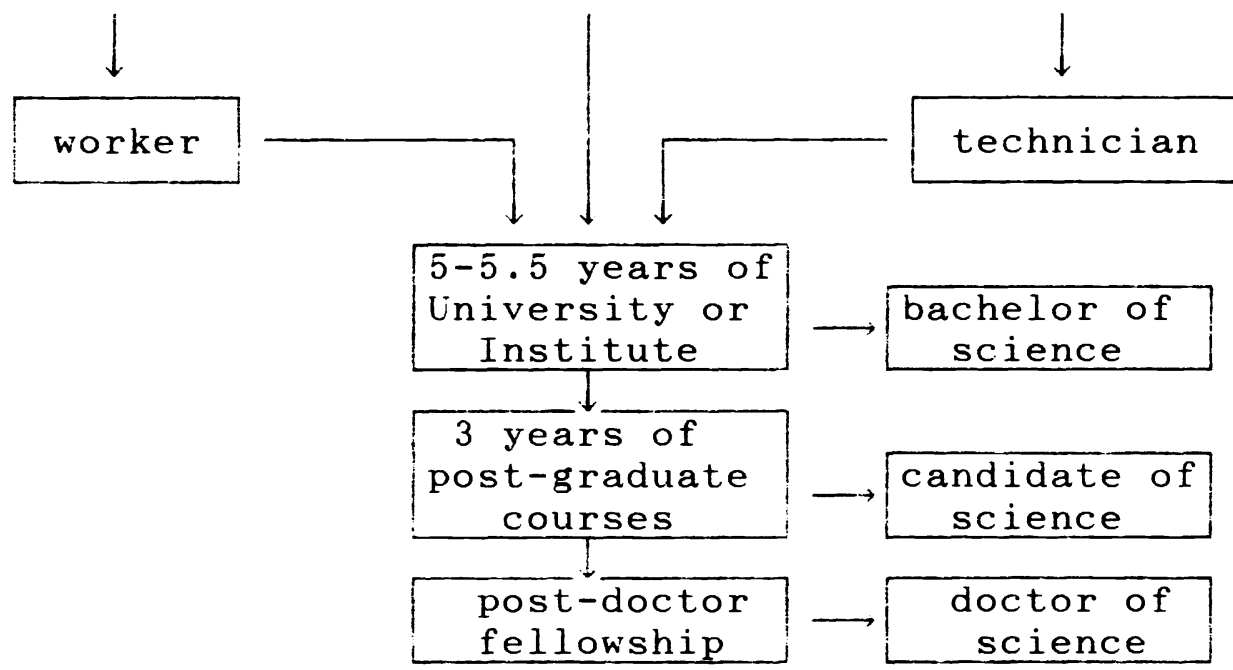

Fig.1. Structure of education in the USSR 
The young men have not had any possibilities to study abroad and therefore all specializations in education are well represented in the USSR. Practically all citizens of the USSR get their education in two stages. Another third stage in 900 iniversities and Institutes grouped about 5 million students in 1990 . It should be noted that there is a single-stage educational system in Universities and Instituties. The period of education is fixed exactly at 5 or 5.5 years. Annually about 800 thousand students graduate from Universities and Institutes. About 35 thousand graduates continue their education at graduate levels (fourth stage). The degree of "Candidate of Science" which is obtained after the defense of the thesis corresponds to a Ph.D. or a Doctor of Technics degree. Candidate of sciences can individually prepare a Doctor's thesis and obtain the Doctor's degree (fifth stage). The requirements for a Doctoral thesis are rather higher than for a Candidate thesis. Usually the preparation of a Doctor's thesis requires 7 or more years.

The main feature of the soviet system of education is the unification of curricula, training programs and textbooks. Until recently all school-children of St.Petersburg, Moscow or Siberian villages were studying with similar textbooks which had been approved by the Ministry of Education. For Universities and Institutes, the Ministry formed the human and fundamental education. Curricula on separate specializations were developed by leading Institutes and Universities with the participation of other representatives. Then they had to be confirmed by the Ministry of University Education. In optical specializations the Institute of Fine Mechanics and Optics was one of such leading institutes. A positive aspect of this system is the high qualification of experts who are developing curricula, educational programs and textbooks. Therefore the resulting quality of their activity is rather high. The main disadvantage of this system is that the curricula it produces do not take into account the peculiarities of separate Institutes: training material, level of students etc. Now such strict regulation has disapeared for many Universities and Institutes and in the near future all of them will form their curricula and programs individually.

One of the important feature of university education in the USSR was the compulsory distribution of graduates from Universities and Institutes with only a small proportion of them having the possibility to be distributed by a direct invitation from firms.

Education in the USSR is free of charge. All the expenses are covered by the government. Only recently firms that employ graduates of Institutes and technical colleges have begun to reimburse partially the expenses. All progressing students get scholarships of 120-200 roubles per month and are provided with a free cot in the hostel. The expense to the government to train one specialist in a University or Institute is 25 thousand roubles. Additional funds from firms are 3-25 thousand roubles. These sums are not sufficient to cover all the expenses for education, especially for educational laboratory equipment. Therefore many 
Institutes finance their training laboratories from funds for scientific research or from contracts with industry.

\section{OPTICAL EDUCATION IN THE USSR}

Optics is studied in all soviet schools. Optics plays an important role in school programs. In special schools besides elementary mathematics some aspects of higher mathematics are considered ( see Table 1 ).

Table 1

Education in mathematics and physics in soviet high school $(10-11-$ th years )

\begin{tabular}{|l|r|}
\hline Discipline & hours \\
\hline Mathematics & $400-600$ \\
Physics & $250-600$ \\
including Optics & $40-120$ \\
\hline
\end{tabular}

The corresponding mathematical apparatus is applied to optical courses, Maxwell's theory is well studied. At the second stage of education in technical colledges or technical schools pupils enter the professions of workers or technicians in optical industry. More than 10 thousand specialists of this type are have being trained each year.

40 Universities and Institutes in 28 cities give high education in optics in the USSR. St.Petersburg, Moscow and Novosibirsk are the traditional centers where optical education was concentrated until 1960. Since the laser has been discovered optical education has developed rapidly and its geography in the USSR now is widely represented. Annually 1200 specialists graduate from 40 Universities and Institutes, among them 400 physicists and 800 optical engineers. It is important to notice that until recently in the USSR four kinds of optical specialist were trained.

- physicists,

- engineer-physicist-opticians,

- engineer-optician-designers,

- engineer-optician-technologists.

Physicists and engineer-physicists are distributed in the usual manner to universities and research laboratories. Engineer-designers are distributed to the departments of industry that deal with the projecting and designing of devices. Engineer-technologists are distributed to optical industries dealing with the production of optical units and devices.

The training for those four trends are different. Each of them is characterized by its own proportions of course cycles (see Table 2). Besides these differences there are significant differences in contents and programs within those cycles. 
Table 2

Proportions of different cycles of disciplines (\%)

\begin{tabular}{|l|c|c|c|c|}
\hline \multicolumn{1}{|c|}{ cycle } & \multicolumn{1}{c|}{$\begin{array}{c}\text { physicists } \\
\text { physicists designers }\end{array}$} & \multicolumn{2}{|c|}{$\begin{array}{c}\text { engineers } \\
\text { phyologists }\end{array}$} \\
\hline physics and & & & 25 & 25 \\
mathematics & 60 & 47 & 15 & 15 \\
engineering & 5 & 5 & 15 & 10 \\
designing & - & 5 & 10 & 15 \\
technology & - & 5 & 5 & 5 \\
economics & - & 3 & 15 & 15 \\
human courses & 15 & 15 & 15 & 15 \\
specialization & 20 & 20 & & \\
\hline
\end{tabular}

The physical-mathematical cycle plays the most important role in the soviet system of optical education. Even in the minimum case for technologists and designers it consists of rather serious courses, as shown in the Table 3. For physicists and engineer-physicists the content of these courses is approximately doubled. As a rule the level of training for those courses is very high as are the requirements. Usually these courses serve as a barrier for students to get access to further education. The main reason of a student's dismissal is the impossibility to pass the mathematics and physics examinations. The rejection of students takes place in the first years of education due to their failure on these courses, and consists of 20-50\% of the student contingent in various Institutes.

Physical-mathematical cycle

Table 3

for engineers and engineers-technologists (in hours)

\begin{tabular}{|ll|}
\hline high mathematics & 500 \\
physics & 300 \\
theoretical mechanics & 120 \\
physical optics (including laser physics) & 250 \\
\hline
\end{tabular}

So the physical-mathematical cycle forms the basis for further education and at the same time is a reliable test for its continuation.

The second cycle which needs to be considered is the cycle of specializations. All the previous cycles - 75-85\% of the total volume of education - provides the fundamental preparation for a 
definite type of activity in optics: scientific research (physicists, engineer-physicists), designing (engineer-designers), production (engineer-technologists). Specialization provides a tight education on concrete fields of optical science (for physicists and engineer-physicists), on concrete types of optical equipment (for engineer-designers) and on concrete types of optical technology (for engineer- technologists).

The specialization usually begins from the fourth year of education and initially takes place along with other cycles. On last 5-th year students have the specialized courses only. Specialization consists of studying a number of courses corresponding to concrete fields of optical science or techniques and of practical work along those directions. As a rule physicists and engyneer-physicists of the $4-t h$ and 5 -th years of education are working $2-4$ days in a week in scientific-research laboratories, taking part in real scientific research. During rest days of a week students are studying in University classrooms. During specialization engineer-designers and engineertechnologists have practice at industries and design bureaus of optical firms. As usual 2-3 practices take 15-20 weeks. During a practice there are no lectures and seminars in classrooms. At practice students are becoming workers or engineers. It should be noticed that scientific-research and practice take place outside the Universities but at those laboratories where later activities of student are expected. Specialization is finished with the defense of a diploma thesis (for physicists) and a diploma design (for engineers) which takes 3-4 months. The student spends this stage of education where he will be employed. Such an organization of specialization allows to adapt the students to their future working places and firms get the possibility to select their future employees. Moreover at firms, the students are usually supervised by leading specialists from scientific laboratories whose scientific level in narrow fields of science is much higher than that of University instructors. That is in general the system of optical education in the USSR which had been used up to the end of the 80-ies. What will happen to this system in the near future? Now our country is changing rapidly. The transformation of the USSR to the Commonwealth of Independent States may lead to the formation of independent systems of education in the republics. Thus various models of education are expected to adopt a two-stage system of education in Universities with 4-year cycles for the BS and 2-year cycles for the MS. The 4-year education is expected to obtain governmental financial support, the training of specialists for the MS degree is expected to be paid by students of firms. If the economical collapse is not stoped and a rapid conversion of optical plants from military to civil production is not made a great decrease in the number of optical specialists graduating is expected. However that will happen without a decrease of financial. support so the material maintenance of education will be improved. Significant changes are expected in relation to international cooperation in education. The development of new technologies for education corresponded first of all to the use of computers and special training laboratories, and it is expected that this will 
continue to be an important feature of optical education in the near future. The development of the technologies requires to combine the efforts of instructors from different Universities and this process is going on in the USSR. You will see some of results we have obtained in the presentations by other authors.

\section{OPTICAL EDUCATION IN ST.PETERSBURG INSTITUTE OF FINE MECHANICS AND OPTICS (St.PITMO)}

St.PITMO is the greatest optical institute in the USSR. It was found in 1930. Its graduates played an leading role in creation of optical industry in the USSR. Each third specialist in optics in the USSR graduated from St.PITMO. Last years about 300 optical engineers have graduated from it annually. The concentration of optical education in a single institute has one important advantage: among of 200 optical professors and 400 researchers and engineers there are specialists practically in all fields of optics and optical technics. Therefore students may be trained in any trends of optics any curricula and programs can be realized. The curriculum for engineer-optician-researcher is represented in Table 4 (curricula for designers and technologists are similar).

Table 4

Curriculum for engineer-optician-researcher in St.PITMO

\begin{tabular}{|c|c|}
\hline Cycles of disciplines & hours \\
\hline $\begin{array}{l}\text { 1.History } \\
\text { 2.Philosophy } \\
\text { 3.Political economy } \\
\text { 4.Politology } \\
\text { 5. Justice } \\
\text { 6. Foreign language (english,french, german) } \\
\text { 7. Sport }\end{array}$ & $\begin{array}{r}200 \\
150 \\
220 \\
130 \\
50 \\
400 \\
700\end{array}$ \\
\hline $\begin{array}{l}\text { Scientific-natural } \\
\text { 8. High mathematics and mathematical physics } \\
9 . \text { General and theoretical physics } \\
\text { 10. Optical physics } \\
11 . \text { Structure and optical properties of matter }\end{array}$ & $\begin{array}{r}900 \\
1100 \\
780 \\
500\end{array}$ \\
\hline $\begin{array}{l}\text { 12. Programming and modelling } \\
13 . \text { Electronics and computers } \\
\text { 14. Optical systems and devices } \\
\text { 15. Design and technology of optical devices } \\
\text { 16. Economics }\end{array}$ & $\begin{array}{l}440 \\
780 \\
350 \\
440 \\
290\end{array}$ \\
\hline Specialization & 1700 \\
\hline
\end{tabular}


This table demonstrates the total amount of hours which student spends for each discipline including self-making work. The work in classrooms is about $60 \%$. All the humanitarian, scientific-natural and technical cycles are finished usually till the 4-th year of education. In the 5-th year students study the disciplines of specialization which are very widely represented. Table 5 demonstrates some special courses delivering now.

Table 5

Main courses delivering in St.PITMO

\begin{tabular}{|ll|}
\hline coherent optics & quantum electronics \\
lasers & optics of lasers \\
solid-state lasers & dye lasers \\
gas lasers & nonlinear optics \\
laser applications & lasers in medicine \\
optoelectronics & optical information processing \\
laser technology & applied spectroscopy \\
spectral device design & technology of optical films \\
\hline
\end{tabular}

Students combine the specialization with work in scientific-research laboratories of St.PITMO, Vavilov's State Institute and others. In 6-th year students are busy entirely with diploma thesis preparing.

\section{CONCLUSION}

The main features of optical education in the USSR are:

- general physical-mathematical (including optical) education in high schools,

- division of specialists training on 3 directions: scientific research (physicist, engineer-physicist), designing (engineerdesigner), production (engineer-technologists),

- wide physical-mathematical education for engineers,

- single-stage system of education with specialization at 4-5-th years,

- long-time scientific (for physicists) and industrial (for engineers) practices on places of future work.

Naturally in the present report we have given a general review of optical education in USSR. We consider it as an introduction to a more detailed acquaintance with the soviet system of optical education which is delivered at the Conference in the reports of my colleagues from the USSR. 